\begin{tabular}{|l|l|}
\hline Recebido: & 03/09/2020 \\
\hline Publicado: & 12/04/2021 \\
\hline
\end{tabular}

\title{
A INTERAÇÃO ENTRE PROFESSOR E ALUNO NA EDUCAÇÃO INFANTIL: REFLEXO NO DESENVOLVIMENTO DA APRENDIZAGEM E SOCIALIZAÇÃO DA CRIANÇA
}

\author{
Cássia Regina Dias Pereirai ${ }^{\mathrm{0}}$ 0000-0003-1572-7002 \\ Universidade Estadual do Paraná - UNESPAR/Campus Paranavaí \\ Aurora Lopes Lorencinii $₫$ 0000-0002-2404-6527 \\ Universidade Estadual do Paraná - UNESPAR/Campus Paranavaí
}

RESUMO: A pesquisa analisou a interação entre o docente e o discente na Educação Infantil, considerando-a um fenômeno legalizado, que objetiva a introdução da criança no contexto sócio educacional. É um estudo de caráter qualitativo e bibliográfico, que permite observar a variação do tema perante o contexto histórico social. As ações educativas efetivadas no âmbito da Educação Infantil favorecem a interação da criança com o meio e as demais pessoas. Essa relação inclui elementos socioculturais, históricos e econômicos que refletem no desenvolvimento do aluno. A pesquisa se fundamenta na história, considerando a interação social imprescindível à educação escolar. O convívio e o diálogo estabelecido entre professor e aluno, na Educação Infantil, podem resultar em implicações de variáveis positivas ou negativas no que diz respeito à iniciativa, participação, segurança e criatividade na resolução das tarefas escolares. Essa educação, como ato e processo de educar e transmitir saberes que assegurem a formação e desenvolvimento físico, cognitivo e sociocultural do aluno, firmouse com a efetivação de políticas públicas como a Constituição Federal de 1988 e a Lei de Diretrizes e Bases n9394/96 que asseguram à criança seu direito a Educação. Ao considerar a infância parte direta da criança no contexto educacional, o perfil do professor da Educação Infantil se diferencia dos demais docentes, uma vez que seu público alvo the exige uma competência polivalente, versátil e multifuncional. Na Educação Infantil o professor é visto pelo aluno como figura de estima, sendo o mediador entre os conhecimentos externos e a apreensão de saberes.

PALAVRAS-CHAVE: Educação Infantil. Professor e Aluno. Aprendizagem e socialização.

\section{THE INTERACTION BETWEEN TEACHER AND STUDENT IN CHILDHOOD EDUCATION: REFLECTION ON THE DEVELOPMENT OF CHILDREN'S LEARNING AND SOCIALIZATION}

\begin{abstract}
The research analyzed the interaction between the teacher and the student in Early Childhood Education, considering it a legalized phenomenon, which aims to introduce the child in the socio-educational context. It is a qualitative and bibliographic study, which allows observing the variation of the theme in the social historical context. The educational actions carried out within the scope of Early Childhood Education favor the child's interaction with the environment and other people. This relationship includes sociocultural, historical and economic elements that reflect on the student's development. The research is based on history, considering the social interaction essential to school education. The coexistence and dialogue established between teacher and student, in Early Childhood Education, can result in implications of positive or negative variables with regard to initiative,
\end{abstract}

participation, security and creativity in solving school tasks. This education, as an act and process of educating and transmitting knowledge that ensures the student's physical, cognitive and sociocultural development and development, was established with the implementation of public policies such as the Federal Constitution of 1988 and the Law of Guidelines and Bases n 9394 / 96 that guarantee children their right to Education. When considering childhood as a direct part of the child in the educational context, the profile of the Early Childhood Education teacher differs from other teachers, since his target audience requires him to be versatile, versatile and multifunctional. In Early Childhood Education, the teacher is seen by the student as a figure of esteem, being the mediator between external knowledge and the apprehension of knowledge.

KEYWORDS: Child education. Teacher and student. Learning and Socialization. 


\section{1-Introdução}

A pesquisa objetiva analisar a interação entre o educador e o educando na Educação Infantil (EI) bem como as possíveis implicações que essa relação produz na/para a socialização da criança e seu processo de aprendizagem, a fim de compreender as influências que esta pode determinar no e para o encaminhamento educacional e social do discente. Para tal, foi desenvolvido um estudo de caráter qualitativo e bibliográfico, permitindo-nos observar a variação do tema perante o contexto histórico social.

O direito à educação no Brasil é garantido pela a Constituição Federal (CF) de 1988, e possui uma legislação específica, a Lei de Diretrizes e Bases da Educação (LDB). Atualmente a EI faz parte da educação básica pública e gratuita brasileira.

No desenvolvimento do processo de escolarização, a relação do professor com o aluno é um fator que, entre outros, e de acordo com o a revisão de literatura feita nesta pesquisa, exerce influência nos resultados da aprendizagem do aluno.

A maneira como o professor interage com seus alunos, principalmente na EI, pode resultar em implicações de variáveis positivas ou negativas no que diz respeito ao desempenho acadêmico, iniciativa e participação quanto ao diálogo com o professor e com os colegas, segurança e criatividade na resolução das tarefas escolares.

É possível observar que, ao avançar de um nível educacional para outro, a interação entre o professor e o aluno tende ao que podemos denominar de "afastamento", ou seja, parece que na EI existe uma ênfase no aspecto afetivo do trato com o aluno. Fato que nos anos finais do Ensino Fundamental já não é observado com evidência.

Esse foi o questionamento que orientou o desenvolvimento da pesquisa, ou seja, quais os possíveis fatores que influenciam na prática pedagógica dos professores da EI refletida na interação afetuosa que a maioria deles demonstra no trato diário com as crianças.

Estudiosos da teoria histórico cultural, como Vygotsky (1896-1934), tomando como base análises e contínuas observações sobre o desenvolvimento da criança e sua formação, apontam:

Desde os primeiros dias do desenvolvimento da criança, suas atividades adquirem um significado próprio num sistema de comportamento social e, sendo dirigidas a objetivos definidos, são refratadas através do prisma do ambiente da criança. O caminho do objeto até a criança e desta até o objeto passa através de outra pessoa. Essa estrutura humana complexa é o produto de um processo de desenvolvimento profundamente enraizado nas ligações entre história individual e história social (VYGOTSKI, 1991, p. 24). 
Nesse sentido os fatores do contexto social tais como o ambiente e a comunidade presente adquirem maior relevância, crescendo e tornando assim, maior visibilidade nas aplicações referentes ao desenvolvimento infantil. Tal fato é elucidado por Antunes (2006, p. 52), ao afirmar que:

Somos como somos pela influência do ambiente em que crescemos dos amigos, dos livros que lemos dos programas a que assistimos e das marcas profundas que deixaram os adultos com quem vivemos. Entre esses adultos incluem-se nossos pais, irmãos e professores, mas também outros, dos quais as vezes, nem nos lembramos.

Dentre as motivações que nos levaram a pesquisar sobre o tema em questão, uma a ser considerada é a busca por uma análise das possíveis práticas pedagógicas que, por consequência, refletem no cotidiano do professor para com o aluno.

Torna-se relevante ao tema, ponderar sobre a educação a partir do um viés educacional contemporâneo, para que seja possível assim, considerar a pluralidade como um fator presente no contexto escolar - visto que a abrangência social a qual a instituição escolar atende, é resultado dos meios de produção de um sistema desigual, que por sua vez, procede em uma sociedade (comunidade) socioeconomicamente plural/desigual (KUHLMANN JR., 2015).

Diante da evidente influência das inter-relações para a formação social, e considerando a escola como um ambiente no qual a criança irá passar grande parte de sua infância, é de fundamental importância analisar a relação entre professor e aluno na EI bem como os reflexos que a mesma gera no desenvolvimento da aprendizagem e na formação social do educando.

Para tanto, o artigo foi dividido em três partes: a primeira, contextualiza a historicidade da EI no Brasil e seus fundamentos nas políticas públicas na atualidade; posteriormente, detecta das influências históricas, sociais e econômicas que embasam a educação infantil, reforçando seus parâmetros primordiais considerados assistencialistas; derradeiramente, identifica os apontamentos que demonstram as interações entre professor e aluno, seu reflexo no desenvolvimento da aprendizagem e na socialização da criança.

\section{A educação infantil no brasil: contextualização histórica e políticas públicas}

A educação escolar como ato ou processo de educar, transmitir saberes e conhecimentos que permeiam o progresso de desenvolvimento pessoal e coletivo do ser perante a sociedade, é 
DOI 10.33872/revcontrad.v2nl.e017 | v. 2, n. 1 | Jan./Jun. 2021

entendida por meio de aplicações metodológicas a fim de assegurar a formação e desenvolvimento físico e intelectual do ser humano que vive em sociedade.

Essa educação expressa o processo de uma formação humanizada, caraterizada pela apropriação dos bens culturais produzidos pela sociedade; remete-se aos conhecimentos culturais-informal/empírico, e aos conhecimentos científico-teóricos, o qual a escola é incumbida de sistematizá-los de maneira que garanta ao sujeito a assimilação destes conhecimentos (BRASIL, 1988).

Toda pessoa desde o momento que nasce, traz em si direito e deveres que viabilizam a sua vida em sociedade. Os mesmos são defendidos por leis que tomam como base a Declaração Universal dos Direitos Humanos datada de 1948-1949. No documento, o direito à educação é destacado como requisito primordial para o desenvolvimento social, político e econômico da pessoa e do local em que ela vive.

No Brasil, a CF de 1988, trata a educação como direito de todos e dever do Estado, tornando-se parte integrante do desenvolvimento de toda criança perante o meio social (BRASIL, 1988).

A caracterização das instituições de Educação Infantil como parte dos deveres do Estado com a educação, expressa já na Constituição de 1988, trata-se de uma formulação almejada por aqueles que, a partir do final da década de 1970, lutaram - e ainda lutam - pela implantação de creches e pré-escolas que respeitem os direitos das crianças e das famílias (KUHLMANN JR., 2015, p. 179).

A organização e o financiamento da EI como responsabilidade do Estado, só foi regulamentada na CF de 1988 e efetivamente implantada após a promulgação da Lei de Diretrizes e Bases da Educação nº 9394/96.

A legislação educacional brasileira que antecedeu a ela- a LDBEN n ${ }^{\circ} 4024 / 61$ e a sua reformulação na $\operatorname{LDB}^{\circ}$ 5692/71, seguindo o contexto político e econômico do período em que foram colocadas em vigência, não deram a devida atenção para a EI e nem versaram sobre sua obrigatoriedade e financiamento.

Com o processo de redemocratização do país a partir dos anos 80 do século XX, ocorreu também a mudança dos fins e objetivos da educação brasileira. No ano de 1996, foi implantada uma nova lei educacional que reorganizou a estrutura da educação escolar do país em dois níveis: a Educação Básica e a Educação Superior. 
A LDB n 9394/96 tornou a EI obrigatória, pública e gratuita, inserida na Educação Básica, organizada em: Educação Infantil, Ensino Fundamental Anos Iniciais, Ensino Fundamental Anos Finais e Ensino Médio.

Art. 29. A educação infantil, primeira etapa da educação básica, tem como finalidade o desenvolvimento integral da criança de até 5 (cinco) anos, em seus aspectos físico, psicológico, intelectual e social, complementando a ação da família e da comunidade (BRASIL, 1996, p. 10).

Em consonância com a LDB n 9394/96, o Referencial Curricular Nacional para a Educação Infantil (RCNEI) foi publicado no ano de 1998 com a pretensão de "[...] apontar metas de qualidade que contribuam para que as crianças tenham um desenvolvimento integral de suas identidades, capazes de crescerem como cidadãos cujos direitos à infância são reconhecidos. " (BRASIL, 1998, p. 07) isto é, sendo ofertado por meio da efetivação do direito à educação.

Ao ingressar na escola, a criança já possui um domínio básico da linguagem; a instituição deve trabalhar com ela considerando o contexto em que está inserida, visto que cada um pode ter enfrentado ou ainda enfrentar dificuldades em sua vida familiar, no convívio social, problemas de saúde ou de desenvolvimento cognitivo ou sensorial (KUHLMANN JR., 2015).

Diante disso, cabe à escola cumprir sua função social, ofertando e garantindo condições de desenvolvimento escolar, favorecendo o progresso em sua educação e inserção de seu alunado no convívio social. Este crescimento educacional, no entanto, não é algo instantâneo, pois o processo educativo deve considerar os fatores sociais ao qual está interligado.

Não se quer também tomar a educação como uma consequência imediata e direta de fatores externos [...] mas compreender as determinações como um processo em que se estabelecem limites, no interior dos quais as pressões e relações de força produzem resultados com significados complexos (KUHLMANN JR., 2015, p. 11).

O período inicial do atendimento voltado à criança, as creches surgiram com intuito de suprir as lacunas sociais, e resultado da falta de tempo e condições da família em atender tais crianças em tempo integral por suas necessidades de inserção no mercado de trabalho. "As instituições pré-escolares foram difundidas internacionalmente a partir da segunda metade do século XIX, como parte de um conjunto de medidas que conformam uma nova concepção assistências [...]” (KUHLMANN JR., 2015, p. 77-78). 
Os pais precisavam ter onde deixar seus filhos, e esperavam que eles recebessem assim, um cuidado assistencial, ou seja, um local em que as crianças receberiam atenção voltada à saúde e formação dos princípios morais básicos. "A educação infantil como direito social, como política pública educativa, resultou de um intenso e longo processo de lutas, no qual os movimentos sociais, sobretudo os feministas, foram grandes protagonistas." (CAMPOS; BARBOSA, 2015, p. 354), pois reivindicavam em movimentos sociais, o atendimento às crianças.

Ao efetivar o direito à educação escolar, considerando sua responsabilidade em promover um desenvolvimento de qualidade, atendendo às necessidades individuais e coletivas, e respondendo a sua obrigatoriedade em auxiliar na construção de um ser capaz de compreender, atuar e participar do seu meio social, essa educação se ampara em Políticas Públicas Educacionais (OLIVEIRA, 2010).

Denominam-se políticas públicas, o conjunto de ações governamentais (seja a nível Federal, Estadual ou Municipal) com a sustentação direta ou indireta das instâncias públicas e privadas. Essas políticas abrangem todas as áreas sociais, como educação, saúde e segurança. Assim está diretamente relacionada à qualidade de vida e cidadania.

É cabível ressaltar, que as políticas públicas podem ser de Estado, sendo amparada pela CF e independe do Governo atuante, ou uma política de Governo, que é relativa a um governo específico, podendo decidir sua efetivação ou não. Considerando suas aplicações se refletem diretamente na sociedade, "A organização social é fundamental para que decisões coletivas sejam favoráveis aos interesses do grupo.” (OLIVEIRA, 2010, p. 03).

As políticas públicas educacionais, por sua vez, são as práticas governamentais direcionadas à educação escolar. Cabe ressaltar que se tratam de políticas públicas educacionais sob a perspectiva da educação escolar, uma vez que ao utilizar apenas o termo educação, podese fazer alusões a quaisquer tipos de conhecimento, aprendido socialmente por meio da família, igreja, rua, trabalho, etc.

Além da CF de 1988 e a LDB nº 9394/96 como políticas públicas educacionais, a Base Nacional Comum Curricular (BNCC), homologada em 2017, indicou a orientação a elaboração dos projetos pedagógicos para a Educação Infantil na prática pedagógica cotidiana com as crianças (BRASIL, 2016).

Esse documento evidencia em si, as competências que os alunos devem atingir no decorrer do processo educacional (CAMPOS; BARBOSA, 2015), além de refletir sobre as práticas pedagógicas e competências gerais da Educação Básica, assegurando para a EI. 
[...] as condições para que as crianças aprendam em situações nas quais possam desempenhar um papel ativo em ambientes que as convidem a vivenciar desafios e a sentirem-se provocadas a resolvê-los, nas quais possam construir significados sobre si, os outros e o mundo social e natural. (BRASIL, 2016, p. 33).

Ademais, a BNCC ressalta que a EI é marco inicial do vínculo escolar na vida da criança, e por isso se faz importante que esta educação corresponda às necessidades e exigências da criança como ser social. Para tanto,

[...] indica os princípios éticos, políticos e estéticos na configuração dos projetos político-pedagógicos das instituições e compreende que são seis os grandes direitos de aprendizagem que devem ser garantidos a todas as crianças brasileiras, quais sejam: conviver, brincar, participar, explorar, comunicar e conhecer-se. (CAMPOS; BARBOSA, 2015, p. 360).

Mediante o exposto, pode-se afirmar que a educação escolar tal como se constitui atualmente, se desenvolveu a partir de suas leis, regimentos, diretrizes, e planos educacionais que culminam em práticas e metodologias cada vez mais aptas e adaptadas a seu foco, isto é, considerando seu público alvo e as condições (históricas, sociais e econômicas) do mesmo. (KUHLMANN JR., 2015).

\section{Influências históricas, sociais e econômicas que embasam a educação infantil e seu currículo}

Ao refletir sobre as influências históricas, sociais e econômicas que embasam a EI, podemos destacar as Diretrizes Curriculares Nacionais para a Educação Básica ressaltando que "O atendimento em creches e pré-escolas como um direito social das crianças se concretiza na Constituição de 1988, com o reconhecimento da Educação Infantil como dever do Estado com a Educação [...]" (BRASIL, 2013, p. 83).

Além da legislação que torna a educação escolar obrigatória, e fixa sua estrutura e organização, existem outros elementos que devem ser analisados quando falamos das interações que constituem o processo educativo na escola. "O fato social da escolarização se explica em relação aos outros fatos sociais, envolvendo a demografia infantil, o trabalho feminino, as transformações familiares, novas representações sociais da infância, etc.” (KUHLMANN JR., 2015, p.16). 
A partir de 1970, a inserção da mão de obra feminina no mercado de trabalho brasileiro favoreceu a atuação da mulher em várias frentes de trabalho e também na escola. Em especial, destacamos que foi trabalhando na escola que ela se tornou uma figura quase unânime no papel de "cuidar" das crianças (ANDRADE, 2010).

É possível inferir que nesse "cuidar" da professora estivesse implícita a extensão das funções do "cuidar materno". Parece que esta interpretação contraditória entre o papel de "professora cuidadora", "funções de maternas" e "funções docentes", favoreceram uma das mazelas da educação escolar, o assistencialismo e consequentemente a descaracterização do trabalho pedagógico e didático do trabalho docente na EI. As Diretrizes Curriculares Nacionais para a Educação Básica ressaltam que o histórico da Educação Infantil foi marcado por refletir

[...] uma fragmentação nas concepções sobre educação das crianças em espaços coletivos, compreendendo o cuidar como atividade meramente ligada ao corpo e destinada às crianças mais pobres, e o educar como experiência de promoção intelectual reservada aos filhos dos grupos socialmente privilegiados (BRASIL, 2013, p. 83).

Essa concepção está atrelada a características de dualidade impressa na educação brasileira desde o período colonial.

Kuhlmann JR. (2015, p.83) discorre que a educação escolar era considerada “[...] não como um direito dos trabalhadores e de seus filhos, mas como uma dádiva [...] propunha-se o atendimento educacional à infância por entidades assistencialistas.”.

A palavra caridade assumiu significados relacionados à religião, ao Estado, ou a um sentimento de ordem individual em relação à pobreza, e assim, "A responsabilidade do Estado para com os pobres passou a ser parâmetro utilizado como prova de civilização, e o fato natural, tornou-se problema social.” (KUHLMANN JR., 2015, p. 56).

Em consonância, a educação escolar se expandiu simultaneamente às mudanças das organizações sociais, visto que atendia a suas necessidades. A escola atuou de maneira conservadora às classes baixas, isso é, ofertando uma educação assistencial, superficial e preparatória para o mercado de trabalho. Assim,

Desenvolvendo e transmitindo concepções de mundo adequadas à manutenção da realidade, o pouco de educação escolar que existia, aliado ao incipiente desenvolvimento científico e tecnológico do momento, dificultava a comunicação, veiculação e expansão de novas ideias e concepções produzidas (VEIGA et al.,1990, p. 14). 
Além dos impactos das relações sociais, o contexto econômico influiu diretamente na educação escolar, uma vez que este campo delimita os interesses governamentais quanto ao desenvolvimento:

É uma experiência educacional do final do século XIX, momento em que as relações capitalistas de produção, amadurecidas pelo ritmo da industrialização (mecanização da produção) e visando a mais-valia, demandavam, por um lado, conhecimento técnico padronizado da mão-de-obra e, por outro, controle ideológico das massas de trabalhadores (OLIVEIRA, 2010, p. 5).

Com isso, a instituição escolar se contradiz ao ser um espaço de/para o desenvolvimento do conhecimento, ampliação do senso crítico e atuação direta da práxis, mas também um meio de controle ideológico. (KUHLMANN JR., 2015).

Aludindo então, o desenvolvimento da EI em seu contexto socioeconômico e histórico, se faz imprescindível considera-lo como "[...] elemento construtivo da história da produção e reprodução da vida social.” (KUHLMANN JR., 2015, p. 15), uma vez ela possibilita o desenvolvimento da criança a partir de sua inserção e vivencia no meio social- o qual a escola está diretamente ligada.

Ao explorar as influências que embasam o histórico da EI, é essencial uma abordagem do currículo que a constitui, bem como sua formação e efetivação. Foi a partir da CF de 1988, que a EI passou a ser veiculada no âmbito educacional e com a promulgação da LDB $n^{\circ}$ 9394/96, como política pública educacional, tem-se a elaboração e articulação do currículo escolar e os critérios organizacionais a esse público, enfatizado em seus artigos 29, 30 e 31 .

Essa lei instituiu o Centro Municipal de Educação Infantil (CMEIs), como o espaço em que a criança é amparada em suas necessidades básicas de subsistência, garantindo as condições de desenvolvimento físico, cognitivo e social, além de seu reconhecimento individual e coletivo (do indivíduo consigo e com o mundo), A Política Nacional de Educação Infantil apresenta que

O currículo da Educação Infantil deve levar e conta, na sua concepção e administração, o grau de desenvolvimento da criança, a diversidade social e cultural das populações infantis e os conhecimentos que se pretendem universalizar (BRASIL, 1994, p. 15).

A partir disso, as instituições ganham visibilidade como um espaço dedicado ao cuidado e a potencialidade dos aspectos físicos, motor e cognitivo, sendo reconhecidas como a fase inicial da educação escolar, ou seja, a criança recebe amparo e estímulos que lhes possibilita um desenvolvimento de qualidade. 
Para a elaboração de um currículo que atenda a EI em suas especificidades, faz-se necessário ir além das leituras de documentos bases, como as Diretrizes Curriculares Nacionais para a Educação Infantil - DCNs, uma vez que o aluno é um sujeito social e histórico que se desenvolve por intermédio das relações sociais com a comunidade pertencente.

Assim, a infância, tal como a educação, não pode ser compreendida fora de seu contexto socioeconômico, histórico e político, como apontado pela Política Nacional de Educação Infantil, elencando que a EI “[...] se fundamenta numa concepção de criança como cidadã, como pessoa em processo de desenvolvimento, como sujeito ativo da construção do seu conhecimento." (BRASIL, 1994, p. 12).

O RCNEI, expõe a articulação estrutural de seu currículo, relacionando os objetivos (gerais e específicos), conteúdos e orientações que regem o processo educativo. Para tanto, estabelece:

[...] uma integração curricular na qual os objetivos gerais para a educação infantil norteiam a definição de objetivos específicos para os diferentes eixos de trabalho. Desses objetivos específicos decorrem os conteúdos que possibilitam concretizar as intenções educativas. O tratamento didático que busca garantir a coerência entre objetivos e conteúdos se explicita por meio das orientações didáticas (BRASIL, 1998, p. 43).

De acordo com as Diretrizes Curriculares Nacionais para Educação Básica (2013), o currículo da EI pode ser posto em prática por meio de metodologias pedagógicas pluralistas, desde que assegurem o desenvolvimento da aprendizagem, favorecendo o acesso aos bens culturais e contato com o homem e a natureza. Essas práticas pedagógicas envolvem indubitavelmente o trabalho do docente, desde seu planejamento à atuação e efetivação da aula.

Assim, inserido no contexto escolar, o professor é visto pelo aluno como figura de maior atenção e estima, uma vez que é o profissional que passa mais tempo com ele, lhe dando atenção e subsídios às necessidades surgentes, sendo o mediador entre os conhecimentos externos e as possíveis assimilações de saberes. (GIMENES; LONGAREZI, 2011).

Tratamos aqui, dos professores atuantes de sua área, com devida formação para tal, não aquele com formações paralelas, tais como auxiliar de desenvolvimento infantil, monitor, babá e recreacionista, uma vez que o atendimento a educação infantil vem apresentando uma crescente demanda, sendo, portanto, necessário discutir o atendimento institucional e legalizado. Perante isso, a LDB no 9394/96 apresenta em seu art. 62 do título VI que 
A formação de docentes para atuar na educação básica far-se-á em nível superior, em curso de licenciatura plena, admitida, como formação mínima para o exercício do magistério na educação infantil e nos cinco primeiros anos do ensino fundamental, a oferecida em nível médio, na modalidade normal (BRASIL, 1996, p. 25).

Portanto, cabe ao professor organizar situações de ensino que proporcionem por meio da dialética um constante movimento no pensamento da criança, de modo que esteja sempre instigando e absorvendo experiências, saberes, informações e competências daquilo que lhes é exposto durante as aulas- quer seja em momentos de brincadeiras, ou não, assim, motivando-a a aprender.

Segundo o RCNEI, para que a aprendizagem infantil se concretize, é preciso que o professor organize sua prática educativa de modo a que:

- a interação com crianças da mesma idade e de idades diferentes em situações diversas como fator de promoção da aprendizagem e do desenvolvimento e da capacidade de relacionar-se;

- os conhecimentos prévios de qualquer natureza, que as crianças já possuem sobre o assunto, já que elas aprendem por meio de uma construção interna ao relacionar suas ideias com as novas informações de que dispõem e com as interações que estabelece;

- a individualidade e a diversidade;

- o grau de desafio que as atividades apresentam e o fato de que devam ser significativas e apresentadas de maneira integrada para as crianças e o mais próximas possíveis das práticas sociais reais;

- a resolução de problemas como forma de aprendizagem (BRASIL, 1998, p. $30)$.

Gimenes e Longarezi (2011, p. 717), discorrem sobre a ação docente, referindo toda prática como uma atividade; em vista disso, relatam como organização estrutural dessa atividade: “[...] sujeito, objeto, motivos, objetivo, sistema de operações, base orientadora da ação, meios para realização da ação, condições de realização e produto." Considerando os possíveis resultados a serem alcançados e necessidades envolvidas, os procedimentos metodológicos devem ser ponderados e organizados de acordo a individualidade de cada criança que poderá receber tal atividade, em cada período de desenvolvimento.

\section{A afetividade na atuação do professor da educação infantil}

O professor da EI apresenta um perfil diferenciado quanto aos demais profissionais da educação, uma vez que seu público alvo lhe exige uma competência polivalente, versátil e 
multifuncional, cabendo assim ao professor, “[...] trabalhar com conteúdos de naturezas diversas que abrangem desde cuidados básicos essenciais até conhecimentos específicos provenientes das diversas áreas do conhecimento.” (BRASIL, 1998, p. 41).

O RCNEI ressalta que a polivalência do professor gera a si próprio uma ação reflexiva constante, de modo a permitir a reflexão e constante reorganização de sua prática metodológica, envolvendo de certa forma, a família e a comunidade de seu alunado. Para tanto, "São instrumentos essenciais para a reflexão sobre a prática direta com as crianças a observação, o registro, o planejamento e a avaliação." (BRASIL, 1998, p. 41).

Além dessa polivalência, o trabalho do docente na EI, é marcado por um viés afetivo, uma vez que suas práticas devem ser planejadas e executadas de modo a atender e respeitar as necessidades e incumbências de seu público alvo.

Por estar em seus primeiros estágios da educação, a criança possui uma necessidade de laços afetivos, tanto no âmbito escolar quanto familiar, por isso a interação se torna um fator facilitador nas relações sociais, e consequentemente, em sala de aula. Assim,

[...] cabe ao professor propiciar situações de conversa, brincadeiras ou de aprendizagens orientadas que garantam a troca entre as crianças, de forma a que possam comunicar-se e expressar-se, demonstrando seus modos de agir, de pensar e de sentir, em um ambiente acolhedor e que propicie a confiança e a autoestima. (BRASIL, 1998, p. 31).

Perante essa incessante necessidade de aceitação da criança por seus professores, "As virtudes e valores do professor que consegue estabelecer laços afetivos com seus alunos repetem-se e intrincam-se na forma como ele trata o conteúdo e nas habilidades de ensino que desenvolve." (VEIGA, 1990, p.146).

Assim, considerando a relevância dos vínculos estabelecidos na EI (entre docentes e discentes), o RCNEI ressalta a importância de se discutir sobre as substituições dos professores atuantes em sala, salientando que:

[...] deve ser pensada e planejada com atenção e antecedência, preparando as crianças para essa situação. Infelizmente, em muitas instituições, a rotatividade de adultos é uma realidade. Quando isso ocorre, é bom que esta transição seja feita paulatinamente com o professor antigo cedendo gradativamente o lugar para o novo. (BRASIL, 1998, p. 82).

Partindo do pressuposto de que a escola não contribui apenas no andamento e expansão cognitiva do aluno, mas influi diretamente no processo de construção da personalidade da 
criança, além do desenvolvimento físico e psicológico e socioafetivo, é preciso considerar que quando se sente segura, ela mantém uma boa relação com seu professor, facilitando sua inserção e participação no processo educativo. "[...] o professor deve planejar e oferecer uma gama variada de experiências que respondam, simultaneamente, às demandas do grupo e às individualidades de cada criança.” (BRASIL, 1998, p. 32).

Paulo Freire (1997), em seu livro Professora sim, tia não, enfatiza a subjetividade do profissional da educação, salientando o papel político-social que desempenham no processo educacional exercido, uma vez que a educação escolar requer comprometimento quanto a formação do cidadão como ser social.

Como educadoras e educadores somos políticos, fazemos política ao fazer educação. E se sonhamos com a democracia, que lutemos, dia e noite, por uma escola em que falemos aos e com os educandos para que, ouvindo-os possamos ser por eles ouvidos também (FREIRE, 1997, p. 62).

Esse diálogo entre docentes e discentes, se torna um meio de agir democraticamente em sala, contribuindo com a formação de sujeitos responsáveis e críticos, de modo que o aluno entenda o valor de ser ouvido e de ouvir o próximo em sua fala. Contudo, "O meu direito à voz não pode ser um direito ilimitado de dizer o que bem entender do mundo e dos outros." (FREIRE, 1997, p. 60) assim, exercendo o professor, a mediação entre si e os demais, explorando os valores sociais envolvidos, como respeito e tolerância.

Com a evidente colaboração do fortalecimento das relações interpessoais, é cabível ressaltar que na EI a aprendizagem está diretamente ligada à afetividade, cabendo assim à escola, criar um ambiente socioafetivo, saudável e receptor para seus alunos.

É preciso e até urgente que a escola vá se tornando um espaço acolhedor e multiplicador de certos gostos democráticos como o de ouvir os outros, não por puro favor mas por dever, o de respeitá-los, o da tolerância, o do acatamento às decisões tomadas pela maioria a que não falte contudo o direito de quem diverge de exprimir sua contrariedade. O gosto da pergunta, da crítica, do debate. $O$ gosto do respeito à coisa pública que entre nós vem sendo tratada como coisa privada, mas como coisa privada que se despreza (FREIRE, 1997, p. 60).

Essas experiências nos primeiros anos de vida, são determinantes para que a criança estabeleça padrões de conduta e formas de lidar com suas emoções, por isso a imprescindível colaboração da afetividade para o desenvolvimento físico e cognitivo do aluno. (GALIANI; GARMS, 2013). 
As instituições de EI integram as funções de cuidar e educar, além de comprometer o docente com o desenvolvimento integral da criança, quanto ao desenvolvimento físico, cognitivo e social do aluno, de modo a aprimorar a qualidade social da educação.

Galiani e Garms (2013, p. 239), em seus estudos referente a prática pedagógica na educação infantil, exploram a psicogenética walloniana, e apontam que esta "[...] abarca quatro campos funcionais na qual se distribui a atividade infantil: afetividade, motricidade, inteligência e a pessoa. "Mediante esses,

A interação entre professores e crianças ultrapassa os limites da prática docente, do ambiente escolar, do semestre e do ano letivo. É, na verdade, uma relação que deixa marcas, e que deve sempre buscar a afetividade como forma de construção das interações e do conhecimento. Assim, considera-se o papel do professor como elo fundamental na busca de relações interpessoais que valorizem o universo afetivo (GALIANI; GARMS, 2013, p. 239).

Desse modo, o docente deve criar um ambiente rico em interações das crianças entre si e com os demais (criança - criança e criança - adulto), de modo a possibilitar o máximo possível de mobilidade das relações sociais expandindo as conquistas socioafetivas e cognitivas dos alunos.

Tais colocações nos permitem determinar que o processo educativo está atrelado as relações sociais estabelecidas entre professor e alunos na sala de aula, além de ser indissociável das demais instâncias sociais envolvidas, ao qual a escola está diretamente ligada. Assim, considerando o pleno desenvolvimento humano na EI, a interação entre professor e aluno produz reflexos no desenvolvimento da aprendizagem e socialização da criança.

\section{Considerações Finais}

Considerando a criança em seu processo de desenvolvimento mediante as relações sociais, a Educação Infantil (EI) é o meio pelo qual ela se insere no contexto educacional a fim de desenvolver-se em diversos seus aspectos.

Essa educação como processo escolar, reconhecida legalmente tal como hoje se efetua, é resultado de constantes lutas pela efetivação das políticas públicas educacionais que asseguram sua prática, tais como a Constituição Federal Brasileira (CF) de 1988, a Lei de Diretrizes e Bases n9394/96 e o Referencial Curricular Nacional para a Educação Infantil.

Não obstante, as lutas sociais geraram influências inegáveis quanto ao desenrolar desse processo. A realidade econômica a partir dos anos 80 do século XX exigiu aumento de 
produção, abertura de mais postos de serviço e a facilitou a inclusão da mão de obra feminina no mercado de trabalho.

A transição econômica, política e social provocou alteração no modo de vida da população brasileira, por um lado facilitou o acesso a bens e produtos, mas por outro aumentou os custos para a manutenção da vida doméstica.

Ou seja, exercer uma atividade remunerada fora de casa, deixou de ser uma opção para as mães de família, tornou-se uma necessidade. Esse contexto envolve outras vertentes que não citaremos aqui, porém nos reportamos a ele, no sentido de sinalizar o encadeamento de circunstâncias que fazem parte da conjuntura em que se estruturou a EI no Brasil.

A escola, ou melhor, a "creche", foi o caminho indicado para liberar as mães para o trabalho. Em outras palavras, as crianças precisavam de um lugar que lhes recebesse e ofertasse o cuidado e promoção de seu desenvolvimento, assim, a institucionalização delas na "creche", supriria a lacuna social e familiar existente.

Perante isso, faz-se necessário ressaltar que tal instituição atuou de forma dicotômica, atendendo à classe baixa de maneira conservadora e superficial, com um viés assistencialista e preparatório para o mercado de trabalho.

Assim, partindo da escola como instituição social, que se desenvolve mediante as influências sociais, econômicas e histórias que permeiam sua realidade, é na CF de 1988 que se dá a efetivação da EI, sua organização e financiamento, tomando-a como um direito social, vinculada à educação escolar, a fim de promover o desenvolvimento individual e coletivo do aluno perante o mundo.

Nela, é possível destacar a atuação do profissional docente para com seus respectivos discentes, bem como as relações intrínsecas ao convívio diário, uma vez que estabelecida a importância da interação entre estes, se faz imprescindível ressaltar o bom encaminhamento educacional produzido.

É preciso evidenciar, que o processo de interação entre professor e alunos na EI, referese ao trabalho e desempenho que o primeiro utiliza em sua aplicação metodológica. Não que se tomar como caminho/objeto e objetivo, a atuação por um viés meramente simplista e sistemático, uma vez que o público alvo exige uma prática condizente com as peculiaridades da criança em desenvolvimento físico, cognitivo, social e escolar.

Cabe ao professor propiciar situações que estimulem a participação, o diálogo, atividades lúdicas que viabilizem e favoreçam aprendizagens orientadas e mútuas, valorizando a expressão da criança para que ela se sinta acolhida, ouvida e ao mesmo tempo aprenda a conviver com as diferenças, agindo com tolerância e respeito à dignidade humana. 
Embora afetividade e desenvolvimento quer seja cognitivo, físico, motor e/ou sócio afetivo, sejam conceitos diferentes, o estudo nos permitiu assentar que são indissociáveis na progressão do aluno em seu contexto educacional. Assim, por meio das influências históricas, sociais e econômicas que a embasam a EI, é possível concluir que este processo educacional se dá de forma contínua e indissociável das relações sociais.

\section{REFERÊNCIAS:}

ANDRADE, Lucimary B. P. de. Educação Infantil: discurso, legislação e práticas institucionais. São Paulo: Cultura Acadêmica, 2010.

ANTUNES, Celso. A linguagem do afeto: Como ensinar virtudes e transmitir valores. 3 ed. Campinas: Papirus, 2006.

BRASIL. Constituição $\quad$ Federal. 1988. Disponível em: <http://www.planalto.gov.br/ccivil_03/constituicao/constituição.htm>. Acesso em: 06 jun. 2018.

BRASIL. MEC. Base Nacional Comum Curricular. Proposta preliminar. Segunda versão revista. Brasília: MEC, 2016. Disponível em: <http://basenacionalcomum.mec.gov.br/documentos/bncc2versao.revista.pdf>. Acesso em: 06 jun. 2018.

BRASIL. MEC. Diretrizes Curriculares Nacionais para a Educação Básica. 2013. Disponível em: <http://portal.mec.gov.br/docman/julho-2013-pdf/13677-diretrizes-educacaobasica-2013-pdf/file>. Acesso em: 28 ago. 2018.

BRASIL. MEC. Lei de Diretrizes e Bases - LDB Lei no 9394/96. 1996. Disponível em: <http://www.planalto.gov.br/ccivil_03/leis/L9394.htm>. Acesso em: 27 mar. 2018.

BRASIL. MEC. Secretaria de Educação Básica. Política Nacional de Educação Infantil: pelo direito das crianças de zero a seis anos à Educação. 1994. Disponível em: <http://portal.mec.gov.br/seb/arquivos/pdf/pol_inf_eduinf.pdf>. Acesso em: 28 ago. 2018.

BRASIL. Ministério da Educação e do Desporto. Referencial Curricular Nacional para a Educação Infantil. v. 1. Introdução. Brasília. 1998. Disponível em: <http://portal.mec.gov.br/seb/arquivos/pdf/rcnei_vol1.pdf>. Acesso em: 10 de jul. 2018.

CAMPOS, Rosânia; BARBOSA, Maria Carmem Silveira. BNC e educação infantil: Quais as possibilidades? Revista Retratos da Escola, Brasília, v. 9, n. 17, p. 353-366, jul./dez. 2015. Disponível em: <http://retratosdaescola.emnuvens.com.br/rde/article/view/585/659>. Acesso em: 20 set. 2018.

FREIRE, Paulo. Professora sim, tia não: cartas a quem ousa ensinar. São Paulo: Olho d’ Água, 1997.

GALIANI, Simone da Silva; GARMS, Gilda Maria Zauhy. A prática pedagógica na educação infantil: Interações afetivas com crianças de 4 e 5 anos na Perspectiva walloniana. In: Congresso Nacional de Educação-EDUCERE, X, Seminário Internacional de Representações Sociais, Subjetividade e Educação-SIRSSE, II. PUC. Curitiba. Anais... 2013.

GIMENES, Olíria Mendes; LONGAREZI, Andréa Maturano. A Formação de Professores na Perspectivas Histórico-Social. In: Congresso Nacional de Educação-EDUCERE, X, Seminário 
Internacional de Representações Sociais, Subjetividade e Educação-SIRSSE, I. PUC. Curitiba. Anais... 2011.

KUHLMANN JR., Moysés. Infância e Educação Infantil: uma abordagem histórica. $7^{\text {a }}$ ed. Porto Alegre: Mediação, 2015.

OLIVEIRA, Adão Francisco de. Políticas Públicas Educacionais: Conceito e contextualização numa perspectiva didática. In: PIZZIO, A.; FRANÇA, G. (Org.) Fronteiras da Educação: desigualdades, tecnologias e políticas. 2010. Disponível em: <http://www.aedmoodle.ufpa.br/pluginfile.php/169363/mod_resource/content/2/OLIVEIRAPol\%C3\%83-ticas\%20p\%C3\%83\%C2\%BAblicas\%20educacionais....pdf $>$. Acesso em: 02 jul. 2018.

VEIGA, Ilma Passos Alencastro et al. Repensando a Didática. 4 ed. Campinas: Papirus, 1990. VYGOTSKI, Lev Semionovich. A formação social da mente. 4 ed. São Paulo: Martins Fontes, 1991. Disponível em: <http://www.egov.ufsc.br/portal/sites/default/files/vygotsky-aformac3a7c3a3o-social-da-mente.pdf>. Acesso em: 19 set. 2018.

\footnotetext{
' Pedagoga, doutora em Educação pela Universidade Estadual de Maringá (UEM), coordenadora do curso de Pedagogia (UniFatecie) e professora Adjunta da Universidade Estadual do Paraná (UNESPAR/Paranavaí). Email: cassiadiaspereira@yahoo.com.br

ii Graduada em Pedagogia pela Universidade Estadual do Paraná - UNESPAR/Paranavaí. Email: auroralorencin@gmail.com
} 